\title{
Correction to: The Clinical Pharmacology of Cladribine Tablets for the Treatment of Relapsing Multiple Sclerosis
}

\author{
Robert Hermann ${ }^{1} \cdot$ Mats O. Karlsson ${ }^{2} \cdot$ Ana M. Novakovic $^{3} \cdot$ Nadia Terranova $^{4} \cdot$ Markus Fluck $^{3} \cdot$ Alain Munafo $^{4}$
}

Published online: 1 August 2018

C) Springer Nature Switzerland AG 2018

Correction to: Clinical Pharmacokinetics

https://doi.org/10.1007/s40262-018-0695-9

Section 1, para 2, lines 2-4 which previously read:

The cladribine prodrug is phosphorylated intracellularly to its active product, 2-chlorodeoxyadenosine triphosphate (Cd-ATP), by deoxycytidine kinase.

\section{Should read:}

The cladribine prodrug is phosphorylated intracellularly to its active product, 2-chlorodeoxyadenosine triphosphate (Cd-ATP), primarily by deoxycytidine kinase.
Section 2.4, para 3, lines 4-6 which previously read: Cd-AMP is further phosphorylated to chlorodeoxyadenosine diphosphate (Cd-ADP), and Cd-ADP is in turn phosphorylated by 5 '-nucleotidase to Cd-ATP $[10,11]$.

\section{Should read:}

Cd-AMP is further phosphorylated to chlorodeoxyadenosine diphosphate (Cd-ADP), and Cd-ADP is in turn phosphorylated to Cd-ATP [10, 11].

The original article can be found online at https://doi.org/10.1007/ s40262-018-0695-9.

Robert Hermann

robert.hermann@cr-appliance.com

1 Clinical Research Appliance (Cr Appliance),

Heinrich-Vingerhut-Weg 3, 63571 Gelnhausen, Germany

2 Department of Pharmaceutical Biosciences, Uppsala University, Uppsala, Sweden

3 Merck KGaA, Darmstadt, Germany

4 Merck Institute for Pharmacometrics, Merck Serono S.A., Switzerland, an Affiliate of Merck KGaA, Darmstadt, Germany 